NBER WORKING PAPER SERIES

\title{
TESTING UNCOVERED INTEREST PARITY AT SHORT AND LONG HORIZONS DURING THE POST-BRETTON WOODS ERA
}

\author{
Menzie D. Chinn \\ Guy Meredith \\ Working Paper 11077 \\ http://www.nber.org/papers/w11077
NATIONAL BUREAU OF ECONOMIC RESEARCH
1050 Massachusetts Avenue
Cambridge, MA 02138
January 2005

We have benefitted from comments from numerous seminar participants at the NBER International Finance and Macro 2001 winter meeting, the IMF, the Federal Reserve Board, the BIS, the Reserve Bank of Australia and several universities. We are grateful to Geert Bekaert, Hali Edison and Gabriel Galati for providing data, and to Advin Pagtakhan for research assistance. The views expressed are solely those of the authors, and do not necessarily represent those of the institutions the authors are associated with. The views expressed herein are those of the author(s) and do not necessarily reflect the views of the National Bureau of Economic Research.

(C) 2005 by Menzie D. Chinn and Guy Meredith. All rights reserved. Short sections of text, not to exceed two paragraphs, may be quoted without explicit permission provided that full credit, including $\odot$ notice, is given to the source. 
Testing Uncovered Interest Parity at Short and Long Horizons during the Post-Bretton Woods Era Menzie D. Chinn and Guy Meredith

NBER Working Paper No. 11077

January 2005

JEL No. F21, F31, F41

\begin{abstract}
$\underline{\text { ABSTRACT }}$
The hypothesis that interest rate differentials are unbiased predictors of future exchange rate movements has been almost universally rejected in empirical studies. In contrast to previous studies, which have used short-horizon data, we test this hypothesis using interest rates on longer-maturity bonds for the U.S., Germany, Japan and Canada. The results of these long-horizon regressions are much more positive - the coefficients on interest differentials are of the correct sign, and most are closer to the predicted value of unity than to zero. These results are robust to the use of different data frequencies, sample periods, yield definitions, and base currencies. We appeal to an econometric interpretation of the results, which focuses on the presence of simultaneity in a cointegration framework.

Menzie D. Chinn

Department of Economics

University of Wisconsin

1180 Observatory Drive

Madison, WI 53706

and NBER

mchinn@lafolette.wisc.edu

Guy Meredith

International Monetary Fund

Washington, DC 20431

gmeredith@imf.org
\end{abstract}




\section{INTRODUCTION}

One of the key stylized facts in the international finance literature is that interest rate differentials fail to predict subsequent exchange rate movements in accord with the "unbiasedness hypothesis". Rather, much more common is the finding that exchange rates move in a manner opposite that predicted; for instance Froot and Thaler (1990) report few cases where the sign of the coefficient on interest rate differentials in exchange rate prediction equations is consistent with the unbiasedness hypothesis, and not a single case where it exceeds the theoretical value of unity. ${ }^{1}$

As pointed out in Chinn and Meredith (2004), one notable aspect of almost all published studies is that the unbiasedness hypothesis has been tested using financial instruments with relatively short maturities, generally of 12 months or less. This focus made sense given the brevity of the floating rate period, and the dearth of longer maturity interest rate data. Since these constraints have been partly relieved in recent years, this paper tests the unbiasedness hypothesis using instruments of longer maturity than those employed in past studies. Our results for the dollar-based exchange rates of the major industrial countries differ strikingly from those obtained using shorter horizons. For instruments with constant maturities of 5 years, all of the coefficients on interest rate differentials in the unbiasedness regressions are of the correct sign. Furthermore, it is never possible to reject the null hypothesis of a slope coefficient equal to unity.

The paper is structured as follows. Section 2 reviews the unbiasedness hypothesis,

${ }^{1}$ Exceptions include Flood and Rose's (1996) results for intra-EMS exchange rates, and Frankel and Poonawala's (2004) findings for emerging markets. Interestingly, Chaboud and Wright (2003) find that UIP holds for major currencies at extremely high frequencies, such as intraday. 
summarizes the existing evidence over short horizons, and provides updated results from 1980 through 2000. Section 3 presents estimates of the unbiasedness hypothesis using data on government bond yields for Germany, Japan, Canada and the United States. Section 4 provides an econometric rationalization for the results that are obtained. Section 5 provides concluding remarks.

\section{A REVIEW OF THE UNBIASEDNESS HYPOTHESIS}

If the conditions for risk-free arbitrage exist, ${ }^{2}$ the ratio of the forward to the spot exchange rate will equal the interest differential between assets with otherwise similar characteristics measured in local currencies,

$$
f_{t, t+k}-s_{t}=\left(i_{t, k}-i_{t, k}^{*}\right)
$$

where $s_{t}$ is the price of foreign currency in units of domestic currency at time $t, f_{t, t+k}$ is the forward value of $s$ for a contract expiring $k$ periods in the future (both in $\operatorname{logs}$ ), $i_{t, k}$ is the $k$-period yield on the domestic instrument, and $i_{t, k}^{*}$ is the corresponding yield on the foreign instrument. Equation (1) is a risk-free arbitrage condition that holds regardless of investor preferences. To the extent that investors are risk averse, however, the forward rate can differ from the expected future spot rate by a premium that compensates for the perceived riskiness of holding domestic versus foreign assets. We define the risk premium, $\eta$, accordingly:

${ }^{2}$ These conditions include identical default risk and tax treatment, the absence of restrictions on foreign ownership, and negligible transactions costs. 


$$
f_{t, t+k}=s_{t, t+k}^{e}+\eta_{t, t+k} .
$$

Substituting equation (2) into (1) then allows the expected change in the exchange rate from period $t$ to period $t+k$ be expressed as a function of the interest differential and the risk premium:

$$
\Delta s_{t, t+k}^{e}=\left(i_{t, k}-i_{t, k}^{*}\right)-\eta_{t, t+k},
$$

Uncovered interest parity (UIP) refers to the proposition embodied in equation (3) when the risk premium is zero, and outcome that would occur if investors are risk-neutral. ${ }^{3}$ In this case, the expected exchange rate depreciation equals the current interest differential. Equation (3) is not directly testable since market expectations of future exchange rate movements are never observable. $^{4}$

Typically, the concept UIP is tested jointly with the assumption of rational expectations in exchange markets. In this case, future realizations of $s_{t+k}$ will equal the value expected at time $t$ plus a white-noise error term $\xi_{\mathrm{t}, t+\mathrm{k}}$ tht is uncorrelated with all information known at $t$, including the interest differential and the spot exchange rate:

$$
s_{t+k}=s_{t, t+k}^{r e}+\xi_{t, t+k},
$$

where $s_{t, t+k}^{r e}$ is the rational expectation of the exchange rate at time $t+k$ formed in time $t$.

${ }^{3}$ Note that some approximations and simplifying assumptions have been made in order to arrive at this expression. See Engel (1996).

${ }^{4}$ Indirect tests of UIP have been performed using surveys of published forecasts of exchange rates. Chinn and Frankel $(1994 ; 2002)$ find mostly positive correlations between the forward discount and the expected depreciation, which is consistent with UIP. 
Substituting equation (4) into (3) yields the following relationship:

$$
\Delta s_{t, t+k}=\left(i_{t, k}-i_{t, k}^{*}\right)-\eta_{t, t+k}+\xi_{t, t+k},
$$

where the left-hand side of equation (5) is the realized change in the exchange rate from $t$ to $t+k$.

Under the unbiasedness hypothesis, the last two terms in equation (5) are assumed to be orthogonal to the interest differential. Thus, in a regression context, the estimated parameter on the interest differential will have a probability limit of unity in the following regression:

$$
\Delta s_{t, t+k}=\alpha+\beta\left(i_{t, k}-i_{t, k}^{*}\right)+\epsilon_{t, t+k} .
$$

The combined assumptions of no risk premium in equation (3) (i.e. that UIP holds) and rational expectations is sometimes termed the "risk-neutral efficient-markets hypothesis" (RNEMH). In this case, the disturbance in equation (6) becomes simply the rational expectations forecast error $\xi_{\mathrm{t}, \mathrm{t} \mathrm{k}}$, which by definition is orthogonal to all information known at time $t$, including the interest differential. The RNEMH is not necessary, however, for the unbiasedness hypothesis to hold. All that is required is that any risk premium and/or non-rational expectations error be uncorrelated with the interest differential. RNEMH, however, does imply the somewhat stronger restriction that no other regressors known at time $t$ should have explanatory power, as the disturbance in equation (6) will be white noise.

Regarding the constant term, non-zero values may be explained by Jensen's inequality, which implies that the expectation of a ratio is not the same as the ratio of the expectations (although this term is likely to be small in practice). Alternatively, relaxing the assumption of risk-neutral investors, the constant term may reflect a constant risk premium demanded by 
investors on foreign versus domestic assets. Default risk could play a similar role, although the latter possibility is less familiar because tests of UIP (as well as CIP) generally use returns on assets issued in offshore markets by borrowers with comparable credit ratings. In contrast, the long-term government bonds used for estimation in Section 3 may not share the same default attributes, so that a pure default risk premium might exist.

As noted above, estimates of equation (6) using values for $k$ that range up to one year resoundingly reject the unbiasedness restriction on the slope parameter. The survey by Froot and Thaler (1990), for instance, finds an average estimate for $\beta$ of -0.88 . Similar results are cited in surveys by MacDonald and Taylor (1992) and Isard (1995), among others.

Table 1 updates estimates of equation (6) for the period 1980Q1 to 2000Q4. The exchange rates of the other six countries were expressed in terms of U.S. dollars, and the 3-, 6-, and 12-month movements in exchange rates were regressed against differentials in eurocurrency yields of the corresponding maturity. ${ }^{5}$ Estimation using the 6- and 12-month horizon data at a quarterly frequency led to overlapping observations, inducing (under the rational expectations null hypothesis) moving average (MA) terms in the residuals. Following Hansen and Hodrick (1980), we used the Generalized Method of Moments (GMM) estimator of Hansen (1982) to correct the standard errors of the parameter estimates for moving average serial correlation of order k-1 (i.e., MA(1) in the case of 6-month data and MA(3) in the case of 12-month data). ${ }^{6}$

${ }^{5}$ Yields and exchange rates were both constructed as the average of bid and offer rates on the last trading day of each quarter. Exchange rate movements and interest differentials are expressed at annual rates.

${ }^{6}$ Under the null, the a rectangular window should be used. A Bartlett window is used instead, to guarantee positive semi-definiteness of the variance-covariance matrix. 
The results confirm the failure of UIP over short horizons, similar to other studies. At each horizon, four of the six estimated coefficients have the "wrong" sign relative to the unbiasedness hypothesis. The average coefficient is around -0.8 , similar to the value in the survey by Froot and Thaler (1990). Panel estimation with slope coefficients constrained to be identical across countries yields estimates ranging from about -0.76 at the 3 -month horizon to -0.54 at the 12-month horizon. ${ }^{7}$ In most cases it is possible to reject the hypothesis that $\beta$ equals unity; in cases where UIP cannot be rejected, the standard errors of the estimated parameters are quite large. All of the adjusted $\mathrm{R}^{2}$ statistics (not reported) are very low, and occasionally negative. Figure 1 provides a graphical depiction of this result for the DM/dollar rate at the 1 year horizon. Interestingly, while there is considerable variation over time in the point estimates of $\beta$, in general there is little evidence that the bias is disappearing, or becoming less pronounced. Breaking the 1980Q1-2000Q4 sample into three equal sub-periods, we re-estimated equation (6) for the 3 month horizon. The point estimates are displayed in Figure 2. For each currency, the three bars denote the B point estimates for the 1980Q1-86Q4, 1987Q1-93Q4 and 1994Q12000Q4 periods, respectively. Statistically significant deviations from the $\beta=1$ null hypothesis are denoted by asterisks (since the data are sampled at a quarterly frequency, the issue of overlapping horizons does not arise in this context).

As is made apparent by the patterns in the Figure, there are many statistically significant deviations from the $\beta=1$ in the latest seven year period. Moreover, the point estimates are more negative in the latter period than in the earliest, with the exception of the U.K. pound/U.S. dollar

${ }^{7}$ These are fixed effects regressions which allow for a different constant across currencies. The standard errors are constructed to allow for cross-currency correlations, as well as serial correlation due to overlapping horizons. See Frankel and Froot (1987) for details. 
rate. Thus, one can safely conclude that the forward rate bias phenomenon has not disappeared at the short horizon.

\section{LONG-HORIZON ESTIMATES}

\subsection{Some basic results}

As noted in the introduction, short-horizon tests of the unbiasedness hypothesis have been facilitated by the availability of interest rate series that correspond closely to the requirements for CIP. Data of comparable quality for longer-horizon instruments generally are much less readily available. In particular, it is difficult to obtain longer-term rates in offshore markets on thicklytraded instruments of a known fixed maturity. For the purposes of this study, then, we have used data that are inherently somewhat less pure from the point of view of the UIP hypothesis. Specifically, these on-shore instruments may be subject to differences in tax regime, capital controls, etc., such that CIP might be violated. Nonetheless, based on the findings by Popper (1993) that covered interest differentials at long maturities are not appreciably greater than those for short (up to one year) maturities, we do not expect that rejections of long-horizon UIP will be driven by deviations from CIP. Another problem is that some of our interest rate series are for debt instruments with maturities that only approximate the posited horizons, and are not the zerocoupon yields that would be exactly consistent with equation (1).

Even if these data tend to exhibit more "noise" than those used for short-horizon tests of UIP, for conventional errors-in-variables reasons we would expect the coefficient on the interest differential in these long-horizon regressions to be biased toward zero, and away from its hypothesized value of unity. Hence, the results we obtain should be conservative in nature. 
Using constant-maturity 5-year yields for Germany, the U.K., Canada, and the U.S., we implement regressions of the form of equation (6) over the 1980Q1-2000Q4 period, to match the sample to that for our short horizon results. The results reported in Table 2 are quite favorable to the UIP hypothesis: for all three of these currencies, the slope coefficients are statistically indistinguishable from the implied value of unity. The estimate for the DM is particularly close to unity at 0.870 , while those for the pound and Canadian dollar are closer to zero. However, in no case can one reject either the null of zero or unit slope.

Figure 3 presents a scatterplot of the relationship, for the DM/dollar rate again. Here, the scatterplot has an upward slope. However, the relationship is by no means tight, as reflected in the uniformly low $\mathrm{R}^{2}$ s (ranging from 0.02 to 0.08 for individual currency pairs). Estimating a fixed effects panel regression yields a point estimate of 0.674 , and $\mathrm{R}^{2}$ of 0.10 . The incorporation of cross currency information, as well as time series, yields a slightly tighter estimate, as indicated by the smaller standard error.

The only other study that we are aware of that test the unbiasedness hypothesis over similar horizons is by Flood and Taylor (1997). Flood and Taylor calculate 3-year changes in and collect average data on medium-term government bonds from the IMF's International Financial Statistics (IFS). The data over the 1973-92 period are then pooled for a sample of 21 countries. They obtain a coefficient on the interest differential of 0.596 with a standard error of 0.195 . Thus the hypotheses that $\beta$ equals either zero or unity can both be rejected. These results are broadly in line with our results.

Other studies have tackled longer horizons. For instance, Chinn and Meredith (2004) examine ten year bond rates over the 1973-1997 period, and found evidence in favor of UIP. 
However, in this case, the sample period is extremely short relative to the horizon length. Alexius (2001) examines 14 long term bond rates of varying maturities for the 1957-1997 period, drawn from $I F S .{ }^{8}$ Her study also finds evidence in favor of the unbiasedness hypothesis at long horizons, although it is difficult to interpret these statistical results as being consistent with uncovered interest parity, as the sample encompasses periods of fixed exchange rates and extensive capital controls.

In any event, it is reassuring that despite data and methodological differences, these results are similar to those obtained in our regressions, suggesting that the difference between short- and long-horizon tests of UIP may be robust across countries, sample periods and estimation procedures.

\subsection{Robustness checks: frequency, sample, types of yields, and base currency}

Given the brevity of the data span relative to the horizons we are investigating, it is reasonable to ask whether the results we have obtained are robust to changes in the data frequency, sample period, interest rate measures, and base currency. First, robustness to data frequency was assessed by resorting to annual data. The last observation from each year was selected, and the corresponding long horizon regressions implemented. Since the number of overlapping horizons is substantially reduced, the small sample bias of the Hansen-Hodrick standard errors should be mitigated considerably. The results are reported in Table 3. All point estimates are positive, with the fixed effects estimate of the slope coefficient is 0.514 .

\footnotetext{
${ }^{8}$ The IFS data are somewhat problematic in that the definitions of the long term bonds is not homogeneous across countries and over time.
} 
Unfortunately, the standard error is sufficiently large that one cannot reject the null of zero (although the null of a unit coefficient cannot be rejected either).

Second, we check whether modifying the sample so that it no longer corresponds to that of the short horizon results has a substantial impact upon our results. Bekaert et al. (2002) have argued that the findings of long horizon UIP is specific to the post-1980's sample, on the basis of their estimates. Hence, we use a sample of 1977Q1-2000Q4 (using 5 year interest rates beginning in 1972). In this case, the coefficients drop somewhat, but remain positive. Moreover, in no case, can the null hypothesis of a unit slope be rejected.

Only by restricting our sample to correspond to Bekaert et al.'s sample (1977Q1-1996Q3 at a quarterly frequency) - and thus dropping the latest observations - can we obtain rejections of the unit slope coefficient. Note that this earlier period (with interest rates corresponding to those beginning in 1972Q1) will more likely reflect the effects of capital controls on onshore interest rates. For instance, Frankel (1984) concludes that capital controls on short term rates were only removed in Japan in the early 1980 's.

Interestingly, adding more recent data serves to strengthen our results. Extending the sample period to 2004Q4 - adding three years worth of data - yields point estimates that are slightly higher than those reported in Table 2 . Hence, we can safely conclude that the positive coefficients we obtain are not artifacts of the specific sample period we select in the post-Bretton Woods era.

An alternative question is whether it is truly the maturity of the debt instrument, rather than the long horizon, that matters. Estimating the same long horizon regressions in (6), but substituting the 3 month interest differential for the 5 year interest differential, does not produce 
the same set of results as obtained before. Half of the point estimates are negative (although not statistically significantly different from zero); and in all cases, the null of $\beta=1$ can be rejected. This is not surprising, as Chen and Mark (1996) found that long horizon regressions using as fundamentals short term interest rates yielded negative coefficients.

Next we assess whether the use of the US dollar as the base currency is driving our results. In order to investigate this avenue, the long horizon regressions are estimated using the Deutschemark as the reference currency. The results, reported in Table 4, indicate that the estimated slope coefficients are once again positive. Although the Canadian dollar/Deutschemark point estimate is close to zero, the null hypothesis of a unit coefficient cannot be rejected. In addition, the Pound/Deutschemark coefficient is very close to one. Hence, we conclude that our long horizon results are not an artifact of using the US dollar as the reference currency.

Finally, we address one complication that arises with the use of long term bond data. One drawback of using bond data - as opposed to offshore deposit rates - is that one has to account for the fact that the reported yields are not zero coupon rates. We checked to see if the results were sensitive to our use of yield to maturity rates for constant maturities instead of zero coupon yields. ${ }^{9}$ In the case of the Deutschemark, the zero coupon data result in slightly higher point estimates $(0.367$ vs. 0.305$)$ and larger standard errors $(0.821$ vs. 0.768$)$. The pound provides a contrast, with a slightly lower estimate $(0.413$ vs. 0.477$)$ and slightly larger standard error $(0.401$ vs. 0.345$)$. The pattern of results is still the same as in Table 2 , so we conclude that our results are to a first approximation robust to the use of yields, rather than zero coupon rates. However, in

\footnotetext{
${ }^{9}$ We thank Geert Bekaert for this suggestion, and for graciously allowing us to use his zero coupon yield series.
} 
order to definitively settle this issue, future research should be devoted to compiling and analyzing appropriately defined interest rate series.

\section{EXPLAINING THE RESULTS ECONOMETRICALLY}

The rather strikingly different results obtained at different horizons should be placed in the context of recent findings that finds that it is much more difficult to reject the null hypothesis of unbiasedness (e.g., Evans and Lewis, 1995), when the unbiasedness proposition is couched in terms of cointegrating relationships. Here, we are not so much concerned with the specific finding regarding cointegration with the posited values, but rather the econometric implications of estimating equation (6). If the expected spot and forward rate are cointegrated, then it must be true that the current spot and forward rate are also cointegrated. It turns out that it is more convenient to work with this representation (Zivot, 2000). According to the Engle-Granger Representation Theorem, one can write this latter cointegrated system as:

$$
\begin{aligned}
\Delta s_{t} & =\gamma_{10}+\Phi_{1}\left[s_{t-1}-\delta_{1} f_{t-1}-\delta_{0}\right]+\sum_{i=1}^{j} \gamma_{1 i} \Delta s_{t-i-1}+\sum_{i=1}^{j} \zeta_{1 i} \Delta f_{t-i-1}+\epsilon_{1 t} \\
\Delta f_{t} & =\gamma_{20}+\Phi_{2}\left[s_{t-1}-\delta_{1} f_{t-1}-\delta_{0}\right]+\sum_{i=1}^{j} \gamma_{2 i} \Delta s_{t-i-1}+\sum_{i=1}^{j} \zeta_{2 i} \Delta f_{t-i-1}+\epsilon_{2 t}
\end{aligned}
$$

where the horizon has been set to one $(k=1)$ for simplicity of exposition. As pointed out by Phillips (1991), single-equation estimation of (7.a) is plagued by asymptotic bias as long as the forward rate is not weakly exogenous. This assertion can be verified by enumerating the steps necessary to convert equation (7) to (6). First, one must assume weak exogeneity of $f$ (implying that $\Phi_{2}=0$, so that we can ignore the second equation). Subsuming the constant into the cointegrating vector, one obtains 


$$
\begin{aligned}
\Delta s_{t} & =b_{0} \Delta f_{t}+\Phi_{1}\left[s_{t-1}-\mu_{1} f_{t-1}-\mu_{0}\right] \\
& +\sum_{i=1}^{j-1} b_{i} \Delta s_{t-i}+\sum_{i=1}^{j-1} c_{i} \Delta f_{t-i}+u_{t}
\end{aligned}
$$

where $b_{i}$ and $c_{i}$ are functions of the variances and covariances of $\epsilon_{1}$ and $\epsilon_{2}$, and $u$ is a function of $\epsilon_{1}$ and $\epsilon_{2}$, and their variances and covariances. In particular, $b_{0}=\sigma_{12} / \sigma_{22}$, which equals zero only when the correlation between the $\epsilon$ 's is zero. Imposing the restrictions $\mu_{0}=0$ and $\mu_{1}=1,{ }^{10}$ equation (8) can be rewritten as:

$$
\begin{gathered}
\Delta s_{t}=-\Phi_{1}\left[f_{t-1}-s_{t-1}\right]+b_{0} \Delta f_{t} \\
+\sum_{i=1}^{j-1} b_{i} \Delta s_{t-i}+\sum_{i=1}^{j-1} c_{i} \Delta f_{t-i}+u_{t}
\end{gathered}
$$

Notice that equation (9) degenerates to equation (6) if and only if $b_{0}=0, b_{i}=c_{i}=0$ for all $i$, as well as $\mu_{0}=0, \mu_{1}=1$ (Moore, 1994; Villanueva, 1999).

To examine whether the standard assumption of weak exogeneity of the forward rate is justified at either the short or long horizons, we generate implicit forward rates using the exact relationship in equation (1), for both the 3 month and 5 year horizons. We then test for cointegration between the forward rate and the future spot rate ${ }^{11}$ using the Johansen (1988) maximum likelihood procedure. The results are reported in Table 5; in Panel 4.a are the cointegration results for the 3 month forward rates and the future spot rates, and in Panel 4.b are

${ }^{10}$ See Brenner and Kroner (1995) complications involved in imposing the $\mu_{0}=0$ restriction in the cointegrating vector.

${ }^{11}$ In principle, either specification is valid asymptotically. Zivot (2000) argues for testing the cointegrating vector involving the contemporaneous forward and spot rate, while Villanueva (1999) reports results demonstrating that lagged forecast errors yield more unambiguous results. 
the corresponding results for the 5 year implicit forward rates.

The first column displays the likelihood ratio for the Trace (top row) and Maximal Eigenvalue (bottom row) statistic. The $10 \%$ critical value for rejecting the null hypothesis of no cointegrating vectors in favor of the alternative of one is 17.85 , using the trace statistic $(13.75$ using the Maximal Eigenvalue statistic). All the currencies evidence cointegration, save the Deutschemark; and here the Maximal Eigenvalue statistic indicates borderline evidence of cointegration. ${ }^{12}$ If the long run unbiasedness hypothesis is imposed, then in all cases save one, the forward -- and not spot -- rate responds to the disequilibrium. The sole exception is the yen, in which case the spot rate responds as well (although in a perverse fashion).

For the 5 year implicit forwards and the corresponding future spot rates, cointegration is detected for the pound, while less evidence of cointegration is detected for the Deutschemark and Canadian dollar. For the pound one obtains the result that at horizons of 5 years, the spot rate responds to the lagged cointegrating vector $\Phi_{1}$ with high statistical significance, while the forward rate does not. That is, long term interest rate differentials are weakly exogenous in this system.

If one uses the more powerful Horvath-Watson (1995) test imposing the unbiasedness hypothesis, one finds that test statistic for the Deutschemark of 4.21 is just below the $10 \%$ critical value of 4.73 for the case with a zero mean in the variables (although it is much less than the corresponding critical value of 8.30 for the possibly more relevant nonzero-mean case). If one were willing to impose the prior of cointegration (see Kremers, Ericsson and Dolado, 1992), then

12 The Horvath-Watson (1994) test also indicates borderline evidence for cointegration. However, if the weakening of the euro in 2000 is included in the sample, then the evidence for cointegration is weakened somewhat. 
the t-statistic on the $\Phi_{1}$ coefficient is statistically significant 1.653 , while that on $\Phi_{2}$ is not significant. Hence, the data thus seem to suggest that the 5 year Deutschemark forward rate -corresponding to the interest differential -- is less endogenous than the spot rate. In contrast, for the Canadian dollar, little evidence of cointegration can be detected, so one cannot interpret the reported coefficients as being meaningful.

For two of the three currencies for which we have data, it appears that the forward rate is weakly exogenous at long horizons, while at short horizons the spot rate is more likely to be weakly exogenous. From a statistical standpoint, this explains some of the differences in the results obtained at short and long horizons.

\section{Conclusions}

We find evidence that the perverse relationship between interest rates and exchange rates is a feature of the short-horizon data that have been used in almost all previous studies. Using longer horizon data, the standard test of UIP yields strikingly different results, with slope parameters that are positive, and insignificantly different from the value of unity. These results hold up against a number of robustness checks, and support the earlier conjectures of Mussa (1979) and Froot and Thaler (1990) that the unbiasedness proposition may better apply at longer horizons.

From an econometric perspective, the differential results can be explained in the context of endogeneity of the right hand side variable. Deciding what type of economic model induces such an endogeneity is a more contentious issue. In a related paper (Chinn and Meredith, 2004), we suggest the difference in the results is consistent with the properties of a conventional 
macroeconomic model. In particular, a temporary disturbance to the uncovered interest parity relationship causes the spot exchange rate to depreciate relative to the expected future rate, leading to higher output, inflation, and interest rates. Higher interest rates are then typically associated with an ex post future appreciation of the exchange rate at short horizons, consistent with the forward discount bias typically found in empirical studies. Over longer horizons, the temporary effects of exchange market shocks fade and the model results are dominated by more fundamental dynamics that are consistent with the UIP hypothesis. ${ }^{13}$

Regardless of the reasons for the failure of the unbiasedness hypothesis at short horizons, from an unconditional forecasting perspective, the conclusion remains that interest differentials are little use as predictors of short-term movements in exchange rates. Even at long horizons, they explain only a relatively small proportion of the observed variance in exchange rates, although one recent study finds that UIP does well compared to other structural models of the exchange rate. ${ }^{14}$

${ }^{13}$ An alternative explanation for these results has been forwarded by Lim and Ogaki (2003), who relies upon exogenously determined segmentation between short and long term bond markets. Alexius and Sellin (2001) argues that UIP holds for holding period returns on long term bonds, suggesting that it is the asset type, rather than horizon, that matters.

${ }^{14}$ Cheung et al. (forthcoming) find that UIP performs best at predicting exchange rates at long horizons, and does well as compared against the sticky price monetary model, a productivity based model, and an ad hoc model incorporating productivity, interest differential, and portfolio effects. 


\section{References}

Alexius, A. (2001), “Uncovered Interest Parity Revisited," Review of International Economics 9(3): 505-517.

Alexius, A. and P. Sellin (2001), "Exchange Rates and Long Term Bonds," Mimeo (Trade Union Institute for Economic Research and Sveriges Riksbank, August).

Bekaert, G., M. Wei and Y. Xing (2002), "Uncovered Interest Rate Parity and the Term Structure,” NBER Working Paper No. 8795 (February).

Brenner, R.J. and K.F. Kroner (1995), “Arbitrage, Cointegration, and Testing the Unbiasedness Hypothesis in Financial Markets," Journal of Financial and Quantitative Analysis, Vol. 30, No. 1, March, pp. 23-42.

Chaboud, A.P. and J. H. Wright (2003), "Uncovered Interest Parity: It Works, But Not For Long," International Finance and Discussion Papers (January).

Chen, J. and N.C. Mark (1996), "Alternative Long-horizon Exchange-rate Predictors," International Journal of Finance and Economics 1(4): 229-50.

Cheung, Y.-W., M.D. Chinn, and A. Garcia Pascual (forthcoming), "Empirical Exchange Rate Models of the Nineties: Are Any Fit to Survive?"Journal of International Money and Finance. Also NBER Working Paper \#9393 (December 2002).

Chinn, M. and J. Frankel (2002), "Survey Data on Exchange Rate Expectations: More Currencies, More Horizons, More Tests," in W. Allen and D. Dickinson (editors), Monetary Policy, Capital Flows and Financial Market Developments in the Era of Financial Globalisation: Essays in Honour of Max Fry, Routledge, London: 145-67.

Chinn, M. and J. Frankel (1994), "Patterns in Exchange Rate Forecasts for Twenty-five Currencies," Journal of Money, Credit, and Banking, Vol. 26, No. 4, November, pp. 75970 .

Chinn, M. and G. Meredith (2004), "Monetary Policy and Long Horizon Uncovered Interest Parity," IMF Staff Papers, Vol. 51 No. 3, November, pp. 409-430.

Engel, C. (1996) "The Forward Discount Anomaly and the Risk Premium: A Survey of Recent Evidence," Journal of Empirical Finance Vol. 3, June, pp. 123-92.

Evans, M.D.D. and K.K. Lewis (1995) "Do Long Term Swings in the Dollar Affect Estimates of the Risk Premium?” Review of Financial Studies, Vol. 8, No. 3, Sept., pp. 709-742. 
Flood, R.P. and A.K. Rose (1996), "Fixes: Of the Forward Discount Puzzle," Review of Economics and Statistics, Vol. 78, No. 4, November, pp. 748-752

Flood, R.P. and M.P. Taylor (1997), "Exchange Rate Economics: What's Wrong with the Conventional Macro Approach?," in J. Frankel, G. Galli, and A. Giovannini (editors) The Microstructure of Foreign Exchange Markets, Chicago: Univ. of Chicago Press for NBER, pp. 262-301.

Frankel, J.A. (1984), The Yen/Dollar Agreement: Liberalizing Japanese Capital Markets. Policy Analyses in International Economics 9, Washington, D.C.: Institute for International Economics.

Frankel, J.A. and K.A. Froot (1987), "Using Survey Data to Test Standard Propositions Regarding Exchange Rate Expectations," American Economic Review Vol. 77, No. 1, pp. 133-153.

Frankel, J.A. and J. Poonawala (2004), "The Forward Market in Emerging Currencies: Less Biased than in Major Currencies," mimeo (Kennedy School of Government, September).

Froot, K.A. and R.H. Thaler (1990), "Foreign Exchange," Journal of Economic Perspectives, Vol. 4, No. 3, Summer, pp. 179-192.

Hansen, L.P. (1982), "Large Sample Properties of Generalized Method of Moments Estimators," Econometrica, Vol. 50, No. 4, pp. 1029-54.

Hansen, L.P. and R.J. Hodrick (1980), "Forward Rates as Optimal Predictors of Future Spot Rates: An Econometric Analysis,” Journal of Political Economy, Vol. 88, pp. 829-53.

Lim, H.-S. and M. Ogaki (2003), "A Theory of Exchange Rates and the Term Structure of Interest Rates," Rochester Center for Economic Research Working Paper No. 504 (Rochester: University of Rochester).

Hodrick, R.J. (1992) "Dividend Yields and Expected Stock Returns: Alternative Procedures for Inference and Measurement," Review of Financial Studies, Vol. 5 No. 3: 357-86.

Isard, P. (1995), Exchange Rate Economics, Cambridge: Cambridge University Press.

Jegadeesh, N. (1991), "Seasonality in Stock Price Mean Reversion: Evidence from the U.S. and the U.K.," Journal of Finance Vol. 46, pp. 1427-1444.

Johansen, S. (1998), "Statistical Analysis of Cointegration Vectors," Journal of Economic Dynamics and Control, Vol. 12, pp. 231-54.

Kremers, J.J.M., N.R. Ericsson, and J. Dolado (1992), “The Power of Co-Integration Tests,” 
Oxford Bulletin of Economics and Statistics, Vol 54, pp. 325-48.

MacDonald, R. and M.P. Taylor (1992), "Exchange Rate Economics: A Survey," IMF Staff Papers, Vol. 39, No. 1, March, pp. 1-57.

Moore, M.J. (1994), “Testing for Unbiasedness in Forward Markets,” The Manchester School, Vol. 62 (Supplement):67-78

Mussa, M. (1979), "Empirical Regularities in the Behavior of Exchange Rates and Theories of the Foreign Exchange Market," in K. Brunner and A.H. Meltzer (editors), Policies for Employment, Prices, and Exchange Rates, Vol. 11 Carnegie-Rochester Conference Series on Public Policy, pp. 9-57.

Osterwald-Lenum, M. (1992), "A Note with Fractiles of the Asymptotic Distribution of the Maximum Likelihood Cointegration Rank Test Statistics: Four Cases," Oxford Bulletin of Economics and Statistics, Vol 54, pp. 461-72.

Phillips, P.C.B. (1991), "Optimal Inference in Cointegrated Systems,” Econometrica, Vol. 59, pp. 283-306.

Popper, H. (1993), "Long-Term Covered Interest Parity-Evidence From Currency Swaps," Journal of International Money and Finance, Vol. 12, No. 4, pp. 439-48.

Zivot, E. (2000) "Cointegration and Forward and Spot Exchange Rate Regressions," Journal of International Money and Finance Vol. 19, No. 6, pp. 785-812. 
Table 1. Short-Horizon Estimates of $\beta$

$$
\Delta s_{t, t+k}=\alpha+\beta\left(i_{t, k}-i_{t, k}^{*}\right)+\epsilon_{t+k} .
$$

\begin{tabular}{|c|c|c|c|}
\hline \multirow[b]{2}{*}{ Currency } & \multicolumn{3}{|c|}{ Maturity } \\
\hline & $3 \mathrm{mo}$. & $6 \mathrm{mo}$. & $12 \mathrm{mo}$. \\
\hline Deutschemark & $\begin{array}{l}-0.809 * \\
(1.134)\end{array}$ & $\begin{array}{l}-0.893 * * * \\
(0.802)\end{array}$ & $\begin{array}{l}-0.587 * * * \\
(0.661)\end{array}$ \\
\hline Japanese yen & $\begin{array}{l}-2.887 * * * \\
(0.997)\end{array}$ & $\begin{array}{l}-2.926 * * * \\
(0.800)\end{array}$ & $\begin{array}{l}-2.627 * * * \\
(0.700)\end{array}$ \\
\hline U.K. pound & $\begin{array}{l}-2.202 * * * \\
(1.086)\end{array}$ & $\begin{array}{l}-2.046 * * * \\
(1.032)\end{array}$ & $\begin{array}{l}-1.418 * * * \\
(0.986)\end{array}$ \\
\hline French franc & $\begin{array}{l}-0.179 \\
(0.904)\end{array}$ & $\begin{array}{l}-0.154 \\
(0.787)\end{array}$ & $\begin{array}{l}-0.009 \\
(0.773)\end{array}$ \\
\hline Italian lira & $\begin{array}{l}0.518 \\
(0.606)\end{array}$ & $\begin{array}{l}0.635 \\
(0.670)\end{array}$ & $\begin{array}{l}0.681 \\
(0.684)\end{array}$ \\
\hline Canadian dollar & $\begin{array}{l}-0.477 * * * \\
(0.513)\end{array}$ & $\begin{array}{l}-0.572 * * * \\
(0.390)\end{array}$ & $\begin{array}{l}-0.610 * * * \\
(0.490)\end{array}$ \\
\hline Constrained panel ${ }^{1}$ & $\begin{array}{l}-0.757 * * * \\
(0.374)\end{array}$ & $\begin{array}{l}-0.761 * * * \\
(0.345)\end{array}$ & $\begin{array}{l}-0.536 * * * \\
(0.369)\end{array}$ \\
\hline
\end{tabular}


Table 2. Long-Horizon Estimates of $\boldsymbol{\beta}$ :

Quarterly data, US dollar base

$$
\Delta s_{t, t+k}=\alpha+\beta\left(i_{t, k}-i_{t, k}^{*}\right)+\epsilon_{t+k} .
$$

\begin{tabular}{|c|c|c|c|c|c|c|}
\hline & $\hat{\alpha}$ & $\hat{\beta}$ & $\begin{array}{l}\text { Reject } \\
\mathrm{H}_{0}: \beta=1\end{array}$ & $\mathrm{R}^{2}$ & DW & $\mathrm{N}$ \\
\hline Deutschemark & $\begin{array}{l}-0.000 \\
(0.012)\end{array}$ & $\begin{array}{c}0.870 \\
(0.694)\end{array}$ & & 0.08 & 0.11 & 84 \\
\hline U.K. pound & $\begin{array}{l}-0.000 \\
(0.015)\end{array}$ & $\begin{array}{c}0.455 \\
(0.385)\end{array}$ & & 0.03 & 0.17 & 84 \\
\hline Canadian dollar & $\begin{array}{l}-0.009 \\
(0.009)\end{array}$ & $\begin{array}{c}0.373 \\
(0.464)\end{array}$ & & 0.02 & 0.08 & 84 \\
\hline Constrained panel $^{1}$ & $\cdots$ & $\begin{array}{c}0.674 \\
(0.412)\end{array}$ & & 0.10 & 0.14 & 252 \\
\hline
\end{tabular}


Table 3. Long-Horizon Tests of Estimates of $\beta$ :

Annual data, US dollar base

\begin{tabular}{|c|c|c|c|c|c|c|}
\hline & $\hat{\alpha}$ & $\hat{\beta}$ & $\begin{array}{l}\text { Reject } \\
\mathrm{H}_{0}: \beta=1\end{array}$ & $\mathrm{R}^{2}$ & DW & $\mathrm{N}$ \\
\hline Deutschemark & $\begin{array}{c}0.001 \\
(0.013)\end{array}$ & $\begin{array}{c}0.608 \\
(0.902)\end{array}$ & & 0.03 & 0.48 & 21 \\
\hline U.K. pound & $\begin{array}{c}0.001 \\
(0.018)\end{array}$ & $\begin{array}{c}0.402 \\
(0.529)\end{array}$ & & 0.02 & 0.67 & 21 \\
\hline Canadian dollar & $\begin{array}{l}-0.006 \\
(0.009)\end{array}$ & $\begin{array}{c}0.608 \\
(0.534)\end{array}$ & & 0.04 & 0.46 & 21 \\
\hline Constrained panel $^{1}$ & $\ldots$ & $\begin{array}{c}0.514 \\
(0.473)\end{array}$ & & 0.06 & 0.57 & 63 \\
\hline
\end{tabular}

Notes: Point estimates from the regression in equation (6) (serial correlation robust standard errors in parentheses, calculated assuming k-1 moving average serial correlation). Sample period: 1980Q1-2000Q4. * $(* *)[* *]$ Different from null hypothesis at $10 \%(5 \%)[1 \%]$ marginal significance level.

${ }_{1}$ Fixed effects regression. Standard errors adjusted for serial correlation (see text). 
Table 4. Long-Horizon Tests of Uncovered Interest Parity:

Quarterly data, Deutschemark base currency

\begin{tabular}{|c|c|c|c|c|}
\hline & $\hat{\alpha}$ & ${ }^{\wedge} \beta$ & $\begin{array}{l}\text { Reject } \\
\mathrm{H}_{0}: \beta=1\end{array}$ & $\mathrm{R}^{2}$ \\
\hline U.K. pound & $\begin{array}{c}0.011 \\
(0.025)\end{array}$ & $\begin{array}{c}0.946 \\
(0.709)\end{array}$ & & 0.12 \\
\hline Canadian dollar & $\begin{array}{l}-0.015 \\
(0.020)\end{array}$ & $\begin{array}{c}0.284 \\
(0.710)\end{array}$ & & -0.01 \\
\hline
\end{tabular}

Notes: Point estimates from the regression in equation 6 (serial correlation robust standard errors in parentheses, calculated assuming k-1 moving average serial correlation). Sample period: 1983Q1-2000Q1. * (**)[***] Different from null hypothesis at 10\%(5\%)[1\%] marginal significance level. 
Table 5. Johansen Cointegration Test Results

$$
\begin{aligned}
\Delta s_{t} & =\gamma_{10}+\Phi_{1}\left[s_{t-1}-f_{t-2}\right]+\sum_{i=1}^{j} \gamma_{1 i} \Delta s_{t-i-1}+\sum_{i=1}^{j} \zeta_{1 i} \Delta f_{t-i-2}+\epsilon_{1 t} \\
\Delta f_{t-1} & =\gamma_{20}+\Phi_{2}\left[s_{t-1}-f_{t-2}\right]+\sum_{i=1}^{j} \gamma_{2 i} \Delta s_{t-i-1}+\sum_{i=1}^{j} \zeta_{2 i} \Delta f_{t-i-2}+\epsilon_{2 t}
\end{aligned}
$$

Panel 5.a: 3 Month Horizon

\begin{tabular}{llcccc}
\hline & LR & $\Phi_{1}$ & $\Phi_{2}$ & $j$ & $\mathrm{~N}$ \\
\hline Deutschemark $^{1}$ & 14.41 & 1.150 & $0.140^{* *}$ & 2 & 84 \\
& 12.79 & $(0.932)$ & $(0.055)$ & & \\
& & {$[1.234]$} & {$[2.565]$} & & \\
Japanese yen & $22.12^{* *}$ & $3.742^{* * *}$ & $0.158^{* *}$ & 2 & 84 \\
& $18.55^{* *}$ & $(1.190)$ & $(0.065)$ & & \\
& & {$[3.144]$} & {$[2.433]$} & & \\
U.K. pound & $21.90^{* *}$ & 2.202 & $0.210^{* * *}$ & 2 & 84 \\
& $15.51^{*}$ & $(1.037)$ & $(0.070)$ & & \\
French franc & & {$[1.124]$} & {$[2.993]$} & & \\
& $20.83^{* *}$ & 0.212 & $0.314 * * *$ & 2 & 84 \\
Italian lira & $14.92^{*}$ & $(0.815)$ & $(0.080)$ & & \\
& & {$[0.260]$} & {$[3.912]$} & & \\
& $29.69^{* * *}$ & -0.450 & $0.313^{* * *}$ & 2 & 84 \\
Canadian dollar & $22.35^{* * *}$ & $(0.681)$ & $(0.082)$ & & \\
& & {$[0.661]$} & {$[3.806]$} & & \\
& $21.24 * *$ & 0.401 & $0.278^{* * *}$ & 2 & 84 \\
& $19.06^{* *}$ & $(0.566)$ & $(0.077)$ & & \\
& & {$[0.709]$} & {$[3.592]$} & &
\end{tabular}

Notes: LR top row (bottom row) is the likelihood ratio for The trace (Maximal Eigenvalue) test of the $\mathrm{H}_{0}$ of zero cointegrating vectors against $\mathrm{H}_{\mathrm{A}}$ of one cointegrating vector, assuming a restricted constant in the cointegrating vector. $17.85,22.05,24.60(13.75,17.63,20.20)$ are the $10 \%, 5 \%$ and $1 \%$ critical values, respectively (Osterwald and Lenum, 1992). Point estimates from OLS regression OLS regression (standard errors in parentheses) [absolute values of the $t$ statistics in brackets]. $j$ is the number of lags in the VAR representation of the cointegrated system. $N$ is the number of observations. Sample period: 1980Q1-2000Q4. * $(* *)[* * *]$ indicates statistical significance at $10 \%(5 \%)[1 \%]$ marginal significance level.

${ }^{1}$ Series cointegrated according to Horvath-Watson (1994) test. 
Panel 5.b: 5 Year Horizon

\begin{tabular}{lccccc} 
& LR & $\Phi_{1}$ & $\Phi_{2}$ & $j$ & $N$ \\
\hline Deutschemark $^{1}$ & 9.97 & $-0.043^{*}$ & 0.037 & 2 & 80 \\
& 7.49 & $(0.026)$ & $(0.027)$ & & \\
& & {$[1.653]$} & {$[1.386]$} & & \\
U.K. pound & 17.46 & $-0.055^{* *}$ & 0.061 & 2 & 84 \\
& 11.89 & $(0.027)$ & $(0.040)$ & & \\
Canadian dollar & 8.94 & -0.014 & $0.051^{*}$ & 2 & 84 \\
& 6.91 & $(0.021)$ & $(0.030)$ & & \\
& & {$[0.661]$} & {$[1.673]$} & &
\end{tabular}

Notes: LR top row (bottom row) is the likelihood ratio for The trace (Maximal Eigenvalue) test of the $\mathrm{H}_{0}$ of zero cointegrating vectors against $\mathrm{H}_{\mathrm{A}}$ of one cointegrating vector, assuming a restricted constant in the cointegrating vector. $17.85,22.05,24.60(13.75,17.63,20.20)$ are the $10 \%, 5 \%$ and $1 \%$ critical values, respectively (Osterwald and Lenum, 1992). Point estimates from OLS regression OLS regression (standard errors in parentheses) [absolute values of the $t$ statistics in brackets]. $j$ is the number of lags in the VAR representation of the cointegrated system. $N$ is the number of observations. Sample period: 1980Q1-2000Q4. * (**)[***] Different from null hypothesis at 10\%(5\%)[1\%] marginal significance level.

* (**)[***] Different from null hypothesis at 10\%(5\%)[1\%] marginal significance level.

${ }^{1}$ Sample period: 1980Q1-1999Q4. 


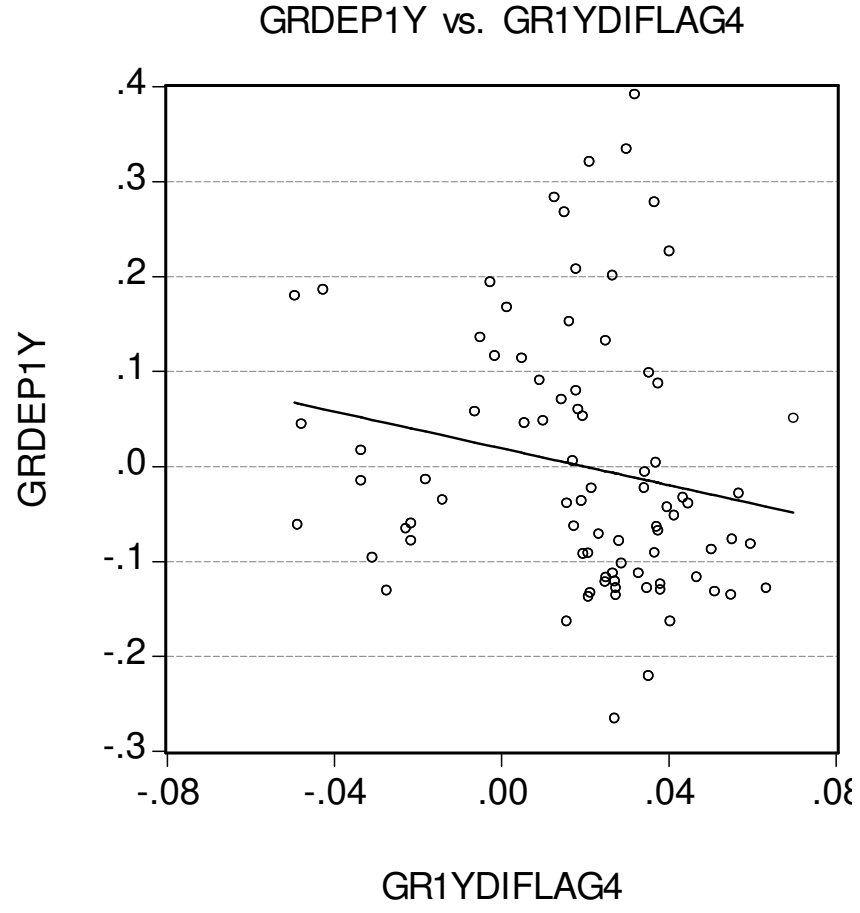

Figure 1: Deutschemark/U.S. dollar depreciation against interest rate differential, 1 year horizon 


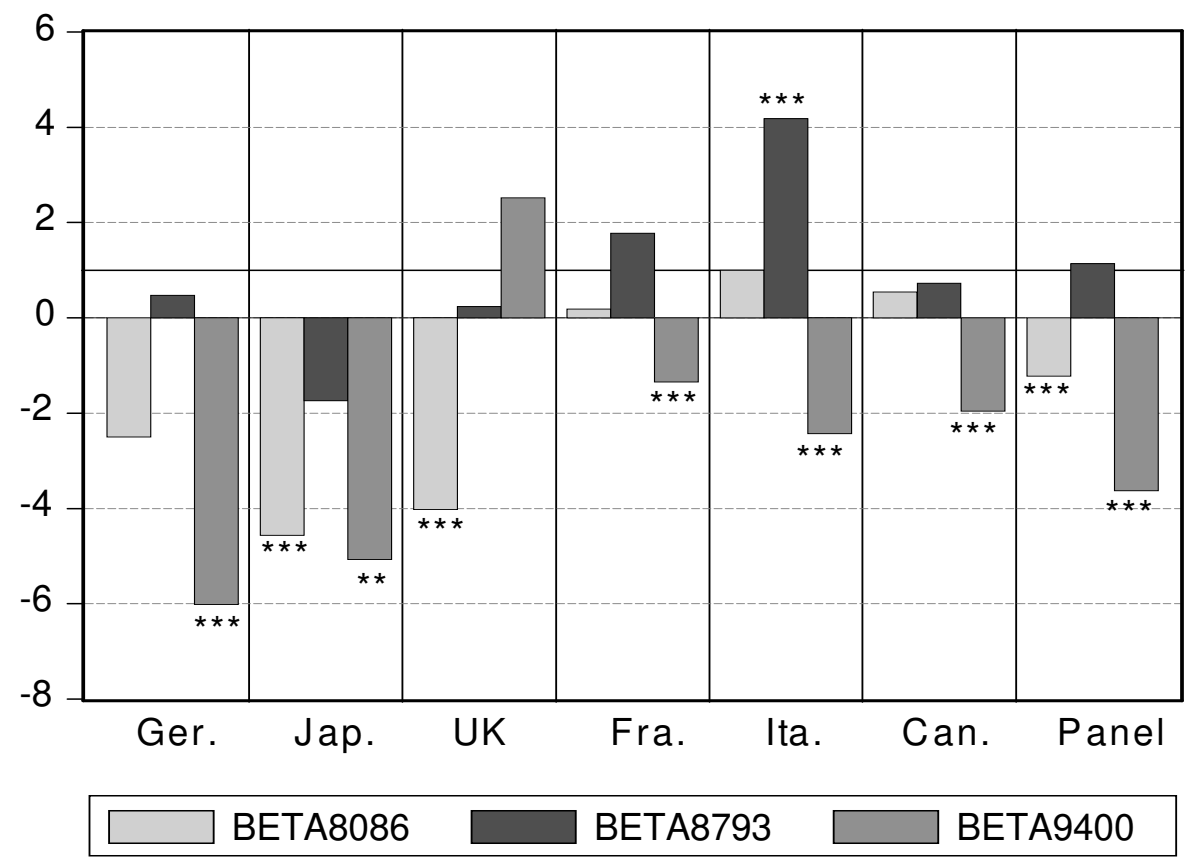

Figure 2: Estimates of $\beta$ at 3 month horizon, for 1980-86, 1987-93 and 1994-2000 sub-samples. *(**)[***] denotes significance at 10\%(5\%)[1\%] significance level for $\mathrm{H}_{0}: \beta=1$. 


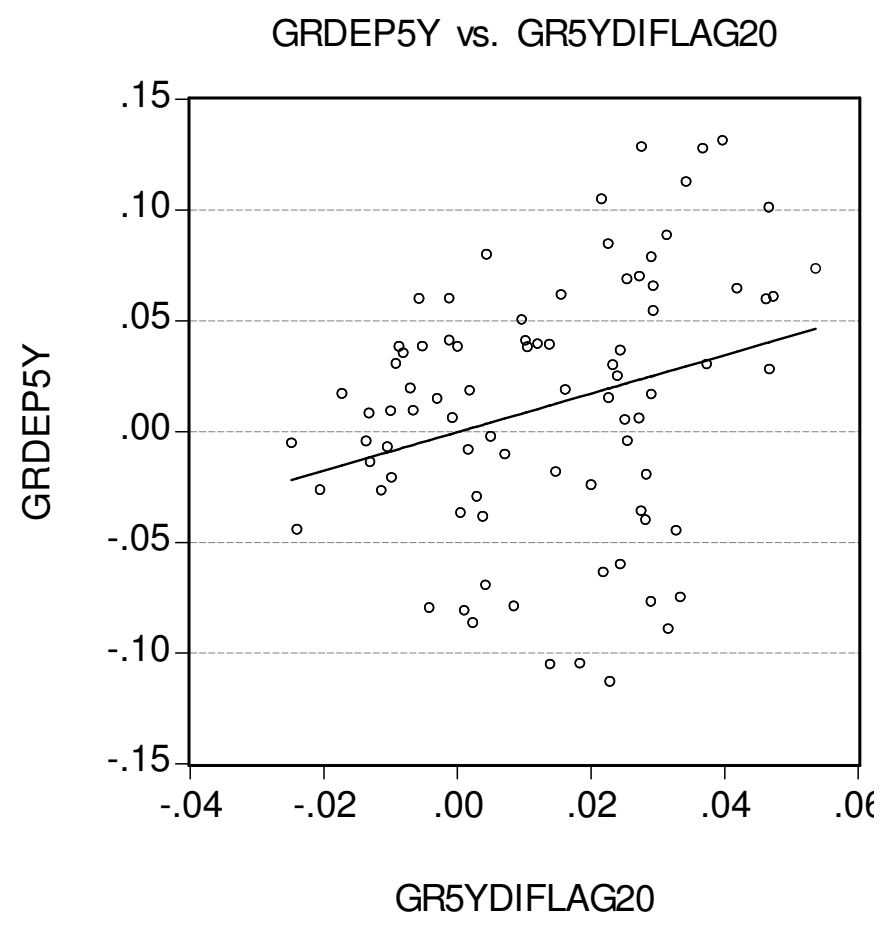

Figure 3: Deutschemark/U.S. dollar depreciation against the interest differential, 5 year horizon. 